\title{
Short communication: Antimicrobial efficacy of intramammary treatment with a novel biphenomycin compound against Staphylococcus aureus, Streptococcus uberis, and Escherichia coli-induced mouse mastitis
}

\author{
Dieter Demon, ${ }^{* 1}$ Koen Breyne, ${ }^{*}$ Guido Schiffer, $†$ and Evelyne Meyer* \\ *Laboratory of Biochemistry, Faculty of Veterinary Medicine, Ghent University, Salisburylaan 133, 9820 Merelbeke, Belgium \\ †AiCuris GmbH \& Co. KG, Building 302, 42117 Wuppertal, Germany
}

\begin{abstract}
Bovine mastitis undermines udder health, jeopardizes milk production, and entails prohibitive costs, estimated at $\$ 2$ billion per year in the dairy industry of the United States. Despite intensive research, the dairy industry has not managed to eradicate the 3 major bovine mastitis-inducing pathogens: Staphylococcus aureus, Streptococcus uberis, and Escherichia coli. In this study, the antimicrobial efficacy of a newly formulated biphenomycin compound (AIC102827) was assessed against intramammary Staph. aureus, Strep. uberis, and $E$. coli infections, using an experimental mouse mastitis model. Based on its effective and protective doses, AIC102827 applied into the mammary gland was most efficient to treat Staph. aureus, but also adequately reduced growth of Strep. uberis or E. coli, indicating its potential as a broad-spectrum candidate to treat staphylococcal, streptococcal, and coliform mastitis in dairy cattle.
\end{abstract}

Key words: antimicrobial therapy, Staphylococcus aureus, Streptococcus uberis, Escherichia coli

\section{Short Communication}

Mammary gland inflammation, or mastitis, provokes detrimental damage to mammary epithelial cells and results in highly impaired milk production. As the most common disease in dairy cows, mastitis is the principal cause of economic losses in the dairy industry (Piepers et al., 2007; Pinzón-Sánchez et al., 2011). Clinical mastitis caused by environmental pathogens such as Streptococcus uberis and Escherichia coli can mostly be cured by antibiotic therapy (Pyörälä, 2009). Nevertheless, the incidence of coliform mastitis has been increasing relentlessly, and multidrug resistance is a typical feature for E. coli (Bradley, 2002; Saini et al., 2012). Although use of the preventive measures in the

Received May 8, 2013.

Accepted August 9, 2013.

${ }^{1}$ Corresponding author: Dieter.Demon@ugent.be well-known 10-point checklist of the National Mastitis Council (NMC, 2006) has significantly improved the incidence of mastitis induced by contagious pathogens such as Staphylococcus aureus, staphylococcal mastitis is still frequently observed (Hogeveen et al., 2010; Zadoks et al., 2011). Therefore, novel antimicrobial therapies remain highly desired for treatment of not only Strep. uberis and E. coli mastitis but also Staph. aureus mastitis.

The antimicrobial AIC102827 belongs to the cyclopeptide biphenomycin class (Ezaki et al., 1985), acting at the level of bacterial protein synthesis; that is, inhibition of the thermo-unstable elongation factor (EF$\mathrm{Tu}$ ). Specifically, the thermo-unstable elongation factor mediates the entry of the aminoacyl-transfer (t)RNA into the free A-site of the ribosome (Agirrezabala and Frank, 2009). This mode of action makes no distinction between gram-positive and gram-negative pathogens, suggesting the potential for efficient antibiotic activity against gram-positive Staph. aureus and Strep. uberis and gram-negative $E$. coli. The objective of the current study was to screen, both in vitro and in vivo, the intramammary efficacy of the novel candidate antimicrobial AIC102827 against the bovine mastitis pathogens Staph. aureus, Strep. uberis, and E. coli. Bovine mastitis studies are time consuming and extremely costly. Therefore, the mouse model for bovine mastitis, which has been recognized as a fast, cheap, and reproducible intermediate in vivo alternative for antimicrobial compound efficacy studies in cattle (Brouillette et al., 2004; Notebaert et al., 2008; Demon et al., 2012), was applied as an elegant screening tool in the current study.

In the present study, the excipient (hydrogel) and different concentrations of AIC102827 (2, 4, 8, and 12 $\mathrm{mg} / \mathrm{mL}$ ) were provided as ready-to-use suspensions by AiCuris GmbH \& Co. (Wuppertal, Germany). Staphylococcus aureus Newbould 305 (ATCC 29740), Strep. uberis NADC C-1 (ATCC 27958), and E. coli P4:O32 were used for infection of mice (challenge isolates). These bacterial strains were originally isolated from clinical mastitis cases (Prasad and Newbould, 1968; Bramley, 1976; McDonald and McDonald, 1976). Over- 
night cultures of the bacteria were diluted in sterile PBS and quantified by flow cytometry (BD Biosciences, Erembodegem, Belgium), as described in detail by Demon et al. (2012). In vitro determination of the MIC of AIC102827 against the challenge isolates Staph. aureus Newbould 305, Strep. uberis NADC C-1, and E. coli $\mathrm{P} 4: \mathrm{O} 32$, and a random selection of recent bovine mastitis field isolates ( $\mathrm{n}=10$ for each species) was performed using the Mueller-Hinton agar dilution assay according to Clinical and Laboratory Standards Institute guidelines (CLSI, 2008). The procedures for mouse mammary gland infection, postmortem mammary gland homogenization, and bacterial quantification have been described recently by our group (Demon et al., 2012). Briefly, CD-1 lactating mice (Harlan Laboratories Inc., Horst, the Netherlands) were anesthetized and intraductally inoculated with approximately $150 \mathrm{cfu}$ of challenge isolate in $100 \mu \mathrm{L}$ of PBS in both glands of the fourth abdominal mammary gland pair. Similarly, $100 \mu \mathrm{L}$ of the excipient and test doses of AIC102827 were instilled at $4 \mathrm{~h}$ after bacterial inoculation. After killing of the mice at $14 \mathrm{~h}$ posttreatment, mammary glands were harvested, weighed, and homogenized on ice in sterile PBS. Bacterial counts (cfu) were obtained after quantification of serial $\log _{10}$ dilutions of mammary gland homogenates on tryptic soy agar plates and transformation of the raw counts into base 10 logarithmic $\left(\log _{10}\right)$ values. The detection limit was $1.7 \log _{10} \mathrm{cfu} / \mathrm{g}$ of gland. In the dose-titration studies, a group with bacteria-infected, excipient-treated mice (excipient control group) was compared with 3 test groups, in which mice were infected with bacteria and treated with a particular dose of AIC102827. In the intra-experimental comparison study, the excipient control group was compared with one test group, in which mice were infected with bacteria and treated with 800 $\mu \mathrm{g} / \mathrm{gland}$ of AIC102827. The groups in the different studies were composed of 4 mice (8 mammary glands), except the 3 mice $(6$ glands) in the $800 \mu \mathrm{g} /$ gland test group in the E. coli dose-titration study. The animal experiments were approved by the Ethical Committee of the Faculty of Veterinary Medicine, Ghent University, Merelbeke, Belgium (EC2009/133). To evaluate the dose-response relationship for the antimicrobial, the effective dose $(\mathbf{E D})_{2 \log 10}, \mathrm{ED}_{4 \log 10}$, protective dose $(\mathbf{P D})_{50}$ and $\mathrm{PD}_{100}$ values were calculated from the dosetitration studies. The $\mathrm{ED}_{2 \log 10}$ and $\mathrm{ED}_{4 \log 10}$ values are the concentrations of AIC102827 needed to reduce the mean bacterial count from the excipient control group by $2 \log _{10}$ and $4 \log _{10} \mathrm{cfu} / \mathrm{g}$ of gland, respectively. The $\mathrm{PD}_{50}$ and $\mathrm{PD}_{100}$ are the doses of $\mathrm{AIC} 102827$ needed to observe, respectively, 50 and $100 \%$ of cleared mammary glands (with mean bacterial count below the detection limit). The model parameters were calculated by nonlinear regression analysis using Microsoft Excel software (Microsoft Corp., Redmond, WA). The models that fitted best; that is, that yielded the highest $\mathrm{R}^{2}$ value, with the dose-response relationship of the antibiotic were polynomial for Staph. aureus Newbould 305 ( $y=$ $\left.7.10^{-5} x^{2}-0.0471 x+8.5966\right)$ and Strep. uberis NADC C-1 $\left(y=5.10^{-6} x^{2}-0.0101 x+6.1556\right)$ and exponential for E. coli $\mathrm{P} 4: \mathrm{O} 32\left(y=8.6977 \mathrm{e}^{-0.002 x}\right)$. The $\mathrm{ED}_{2 \log 10}$ and $\mathrm{ED}_{4 \log 10}$ values were then computed by calculating $x$ from these models, in which $y$ is replaced by $z-2$ and $z$ -4 , respectively, with $z$ being the mean bacterial count $\left(\log _{10} \mathrm{cfu} / \mathrm{g}\right.$ of gland) from the excipient control group. To determine the volume of the secretory fluid in the bacterially infected mammary gland, mice $(\mathrm{n}=8)$ were intraductally infected with Staph. aureus Newbould 305 as described. Mammary glands $(\mathrm{n}=15 ; 1$ gland was omitted due to improper inoculation) were harvested at $4 \mathrm{~h}$ postinoculation. The glands were weighed, placed on a cell strainer of $40 \mu \mathrm{m}$, and centrifuged at 2,000 $\times g$ for $1 \mathrm{~h}$ to expel their milk content. After centrifugation, the glands were weighed again and subtracted from the gland weight before centrifugation. The resulting weight was divided by the density of mouse milk (1.06 $\mathrm{mg} / \mathrm{mL}$ ) to calculate the corresponding volume.

Table 1 reports MIC values of AIC102827, the newly formulated antimicrobial from the biphenomycin class, against the 3 major bovine mastitis pathogens. The MIC values of AIC102827 against 10 bovine mastitis field isolates of Staph. aureus, Strep. uberis, and E. coli were 4 to $8, \geq 16$, and 2 to $4 \mu \mathrm{g} / \mathrm{mL}$, respectively. These MIC values illustrate efficient in vitro antimicrobial activity of AIC102827 against Staph. aureus and E. coli, but less adequate activity against Strep. uberis. The adequate activity of AIC102827 against Staph. aureus and $E$. coli indicates its ability to act against both gram-positive and gram-negative bacteria. However, the inadequate activity against Strep. uberis shows that, although AIC102827 inhibits a universal bacterial growth mechanism, species-specific characteristics are involved in the susceptibility to the antimicrobial. The MIC values of AIC102827 against the mouse mastitis challenge isolates of Staph. aureus Newbould 305, Strep. uberis NADC C-1, and E. coli $\mathrm{P} 4$ :O32 were $4,>16$, and $4 \mu \mathrm{g} / \mathrm{mL}$, respectively, and strongly correlated with the sensitivity of the bovine mastitis field isolates, indicating the suitability of the latter as reference strains in the current in vivo mouse mastitis study. The in vivo dose-responses of mouse mastitis induced by Staph. aureus Newbould 305, Strep. uberis NADC C-1, and E. coli $\mathrm{P} 4: \mathrm{O} 32$ to hydrogel-suspended AIC102827 were analyzed in 3 separate dose titration studies (Figure 1A to $\mathrm{C}$ ). These data were used to calculate the $\mathrm{ED}_{2 \log 10}$, $\mathrm{ED}_{4 \log 10}, \mathrm{PD}_{50}$, and $\mathrm{PD}_{100}$ values (Table 1). The $\mathrm{ED}_{2 \log 10}$ value (corresponding to $99 \%$ bacterial clearance) of 
AIC102827 was 45, 215, and $130 \mu \mathrm{g} /$ gland for Staph. aureus, Strep. uberis, and E. coli, respectively. These values indicate that AIC102827 can clear 99\% of the Staph. aureus bacteria from the lactating mammary gland, even at a low dose, whereas a higher dose is needed to clear Strep. uberis and E. coli. In line with this finding, the $\mathrm{ED}_{4 \log 10}$ value (corresponding to $99.99 \%$ bacterial clearance) of AIC102827 was 100, 530, and 310 $\mu \mathrm{g} / \mathrm{gland}$ for Staph. aureus, Strep. uberis, and E. coli, respectively. The $\mathrm{PD}_{50}$ and $\mathrm{PD}_{100}$ values of AIC102827 for the 3 mouse mastitis challenge isolates additionally indicated that its intramammary treatment is more efficient in curing glands infected by Staph. aureus than by Strep. uberis or E. coli. An intra-experimental study with one selected dose of AIC102827 was then performed to evaluate reproducibility and compare the antimicrobial efficacy of AIC102827 between the 3 pathogens in a study with minimal variability of experimental parameters such as the health status of the mice and environmental conditions such as humidity and temperature (Figure 1D). An AIC102827 dose of $800 \mu \mathrm{g} /$ gland was selected for the intra-experimental comparison study, because it showed reduction of the bacterial load virtually to the detection limit in most mammary glands in the separate dose-titration studies. For all 3 species, the mean bacterial counts $\left(\log _{10}\right.$ $\mathrm{cfu} / \mathrm{g}$ of gland) in the intra-experimental study (Figure 1D) closely approximated their respective means in the dose-titration study (Figure 1A to C), illustrating the reproducibility of our data. Together, our in vitro MIC and in vivo mouse data indicate adequate efficacy of AIC102827 against the 3 mouse mastitis challenge isolates.

The antimicrobial AIC102827 indicated similar in vitro MIC for Staph. aureus Newbould 305 and E. coli $\mathrm{P} 4$ :O32. Consequently, analogous in vivo antimicrobial activity was expected against both pathogens. However, AIC102827 was less effective against E. coli than against Staph. aureus in the in vivo study. In contrast, efficacy against Strep. uberis in vivo was higher than expected based on the in vitro data. Together, these observations indicate that the mammary gland environment positively influences antimicrobial activity against the gram-positive bacteria and negatively affects activity against the gram-negative E. coli. A possible explanation for the increased in vivo activity against Staph. aureus and Strep. uberis could be that the concentration of AIC102827 in milk greatly exceeds the in vitro MIC required to inhibit bacterial growth. To assess this hypothesis, we evaluated the intramammary antimicrobial concentration in the bacterially infected mammary gland at $4 \mathrm{~h}$ postinfection; that is, at the time of compound treatment. On average, 52 $\mu \mathrm{L}( \pm 19 \mu \mathrm{L})$ of secretory fluid was observed in the infected mammary gland, which had a mean weight of $635 \mathrm{mg}( \pm 163 \mathrm{mg})$ at the time of treatment (Figure 2). Although substantial variability in gland volume was seen, these data indicate that the concentration of the compound suspension, which is injected in a volume of $100 \mu \mathrm{L}$, is reduced by approximately $30 \%$ after injection in the mammary gland. Treatment with the $8 \mathrm{mg} / \mathrm{mL}$ suspension led to a concentration of approximately 5 $\mathrm{mg} / \mathrm{mL}$ in the mammary gland and is several-hundredfold higher than the concentration that is used in in vitro experiments (in the $\mu \mathrm{g} / \mathrm{mL}$ range) to determine the MIC values, corroborating this hypothesis. However, this does not explain the potentially lower in vivo antimicrobial efficacy against $E$. coli. The milk environment of the mammary gland is known to influence the in vivo efficacy of an antimicrobial agent. Critical aspects influenced by the milk matrix are local immune cell interactions, bacterial growth, and pharmacokinetic parameters (adsorption, distribution, metabolism, and excretion) of the antimicrobial (Brouillette and Malouin, 2005; Gehring and Smith, 2006; Van Bambeke et al., 2006). In this context, the extracellular residing

Table 1. Antimicrobial efficacy of AIC102827 against Staphylococcus aureus, Streptococcus uberis, and Escherichia coli evaluated in vitro by determination of MIC values and in vivo by analyzing effective and protective doses using the mouse mastitis model

\begin{tabular}{|c|c|c|c|c|c|c|}
\hline \multirow[b]{2}{*}{ Species } & \multicolumn{2}{|c|}{$\operatorname{MIC}^{1}(\mu \mathrm{g} / \mathrm{mL})$} & \multicolumn{2}{|c|}{ Effective dose $^{2}(\mu \mathrm{g} /$ gland $)$} & \multicolumn{2}{|c|}{ 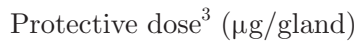 } \\
\hline & $\begin{array}{l}\text { Field } \\
\text { isolates }\end{array}$ & $\begin{array}{l}\text { Mouse mastitis } \\
\text { challenge }\end{array}$ & $\mathrm{ED}_{2 \log 10}$ & $\mathrm{ED}_{4 \log 10}$ & $\mathrm{PD}_{50}$ & $\mathrm{PD}_{100}$ \\
\hline Staph. aureus & $4-8$ & 4 & 45 & 100 & 200 & 800 \\
\hline Strep. uberis & $\geq 16$ & $>16$ & 215 & 530 & $400-800$ & 800 \\
\hline E. coli & $2-4$ & 4 & 130 & 310 & $400-800$ & $>800$ \\
\hline
\end{tabular}

${ }^{1}$ Minimal concentrations of the antimicrobial required to inhibit visible growth of Staph. aureus $(\mathrm{n}=10)$, Strep. uberis $(\mathrm{n}=10)$, or E. coli $(\mathrm{n}=$ 10) field isolates and Staph. aureus Newbould 305, Strep. uberis NADC C1, or E. coli P4:O32 mouse mastitis challenge isolates.

${ }^{2} \mathrm{ED}_{2 \log 10}$ and $\mathrm{ED}_{4 \log 10}$ values are the concentrations of AIC102827 needed to reduce the mean bacterial count (log 10 cfu/g of gland) from the excipient control group by $2 \log _{10}$ and $4 \log _{10}$, respectively.

${ }^{3}$ The $\mathrm{PD}_{50}$ and $\mathrm{PD}_{100}$ values are the doses of $\mathrm{AIC} 102827$ needed to observe, respectively, $50 \%$ and $100 \%$ of cleared mammary glands; that is, with a count $\left(\log _{10} \mathrm{cfu} / \mathrm{g}\right.$ of gland) below the detection limit. 
A
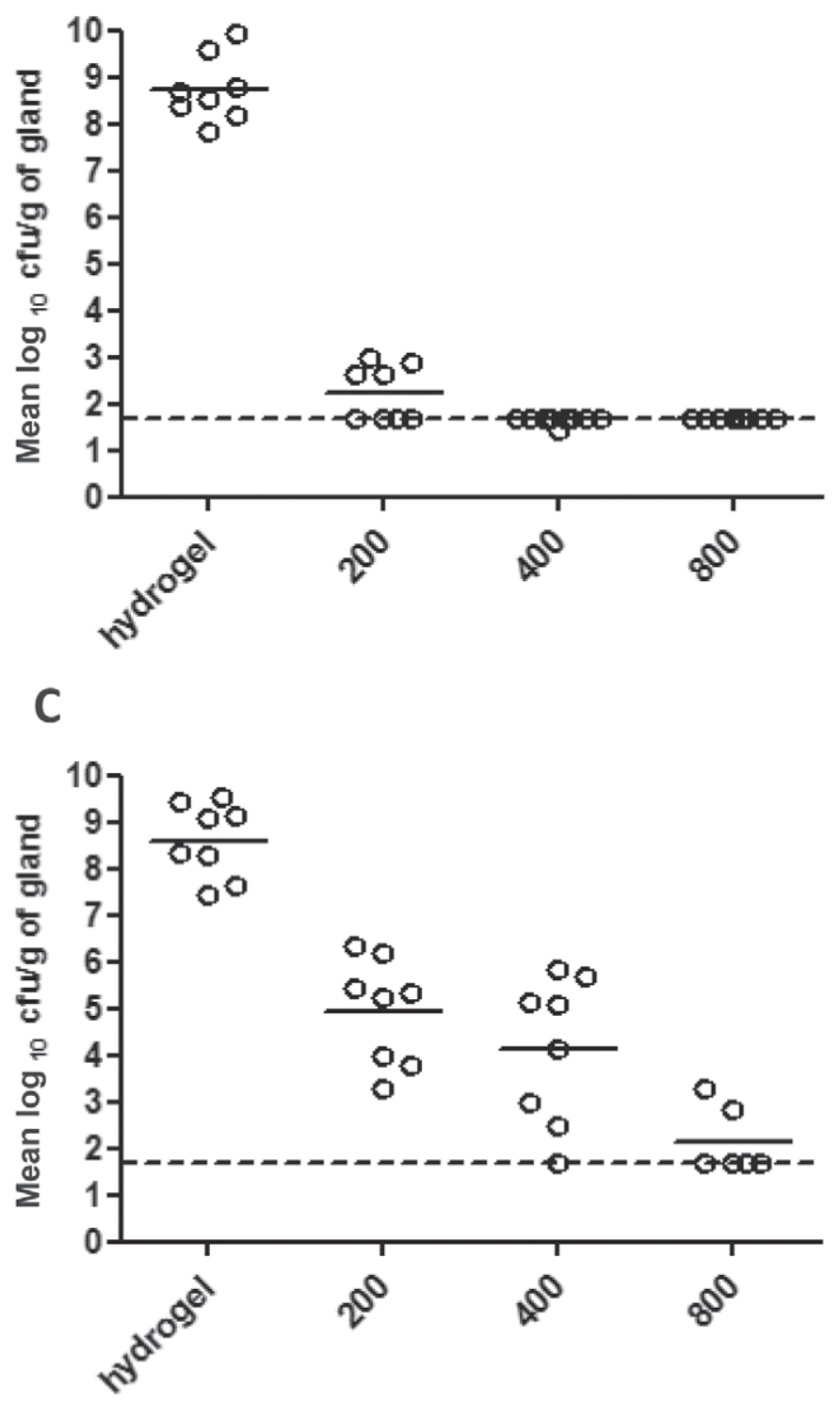

AIC102827 $(\mu \mathrm{g} / \mathrm{gland})$
B
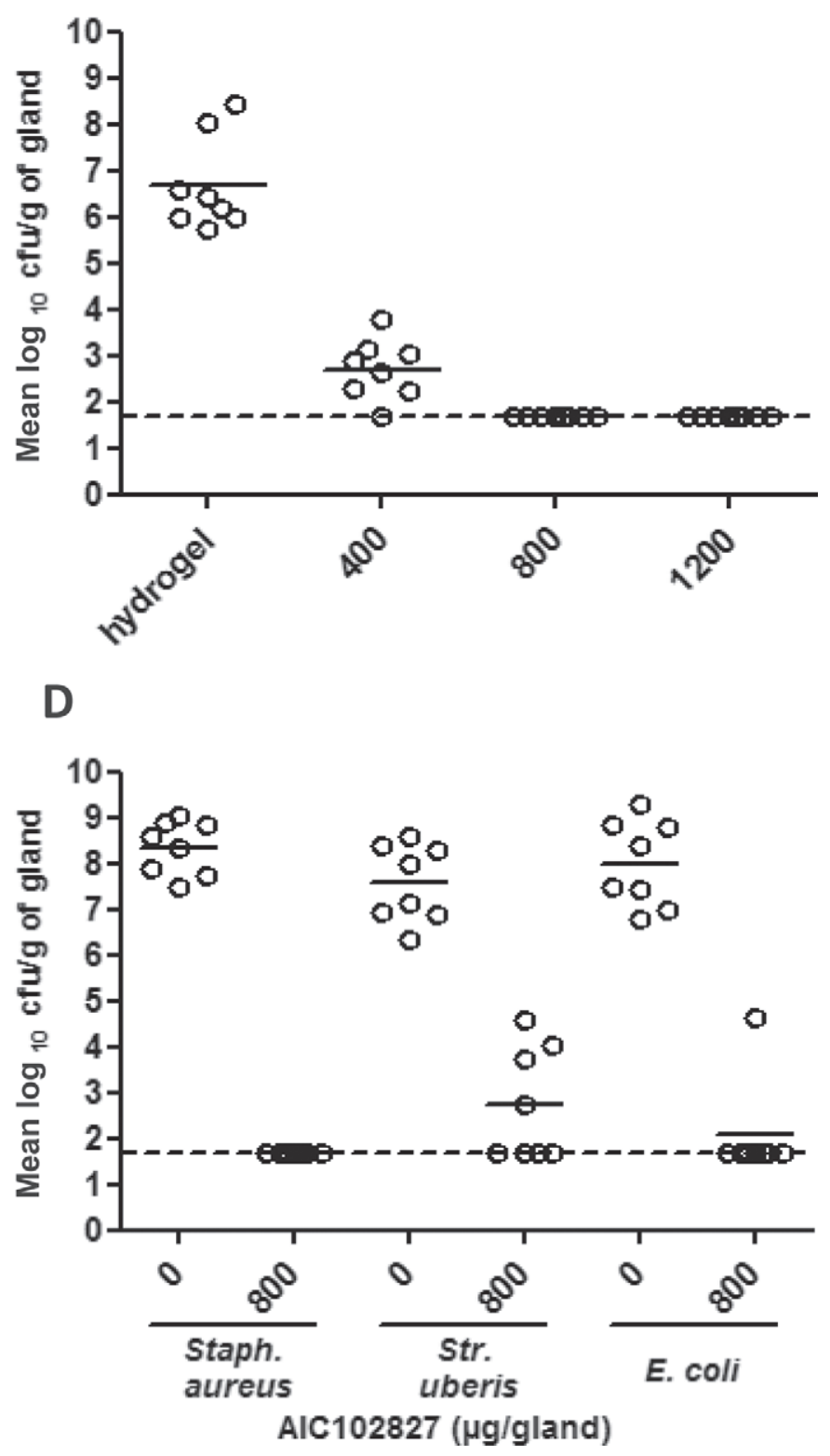

Figure 1. Staphylococcus aureus Newbould 305 (A), Streptococcus uberis NADC C-1 (B), and Escherichia coli P4:O32 (C) count reduction ( $\log _{10} \mathrm{cfu} / \mathrm{g}$ of gland) at $14 \mathrm{~h}$ posttreatment in infected mouse mammary glands treated with increasing doses of the novel antimicrobial agent AIC102827; (D) intra-experimental comparison study indicating Staph. aureus Newbould 305, Strep. uberis NADC C-1, and E. coli P4:O32 count reduction $\left(\log _{10} \mathrm{cfu} / \mathrm{g}\right.$ of gland) at $14 \mathrm{~h}$ posttreatment in mouse mammary glands treated with $800 \mu \mathrm{g} /$ gland AIC102827. Dashed line indicates detection limit. Hydrogel = excipient only (no AIC102827).

E. coli has become better adapted to the milk environment than the typically intracellularly residing grampositive pathogens Staph. aureus and Strep. uberis, at least partially clarifying the potentially lower than expected antimicrobial efficacy against E. coli observed in the current study. The observation that the in vitro antimicrobial activity of AIC102827 for Staph. aureus, Strep. uberis, or E. coli did not directly correlate with its in vivo efficacy corroborates previous reports by our group and others (Apparao et al., 2009; Pyörälä, 2009; Demon et al., 2012). Hence, our current data again highlight the importance of in vivo studies in addition to in vitro studies to screen antimicrobial candidates.

Several studies in cows describe strain-specific associations for Staph. aureus, Strep. uberis, and E. coli with respect to clinical signs, persistence, and response 


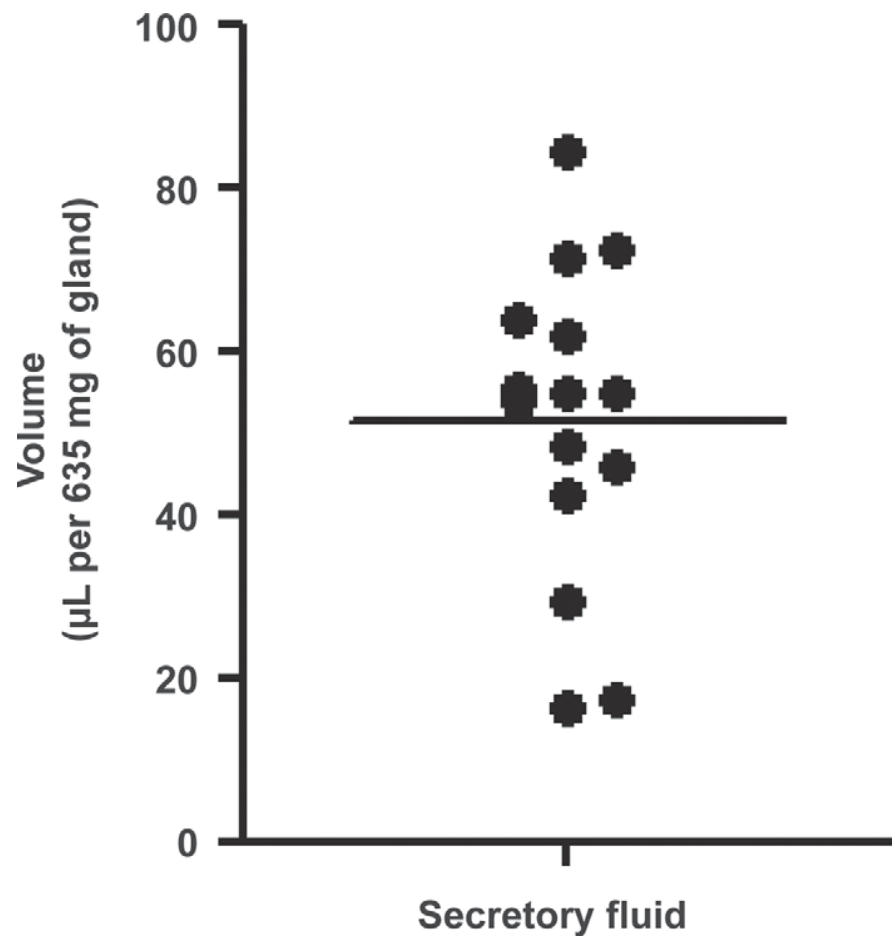

Figure 2. Volume of milky secretory fluid in the Staphylococcus aureus Newbould 305-infected mammary gland $(\mathrm{n}=15)$ at $4 \mathrm{~h}$ postinfection. Volume is presented as microliters per $635 \mathrm{mg}$ of mammary gland, because $635 \mathrm{mg}$ is the average weight of an infected mammary gland at the moment of antimicrobial treatment.

to therapy (Saini et al., 2012; and reviewed by Zadoks, 2007; Zadoks et al., 2011). Therefore, systematic comparison of the efficacy of antimicrobials against mastitis induced by different clinically relevant bovine strains would greatly help to guide veterinary practitioners in combining the most efficacious therapeutics as a strategy to target, for example, particular cases involving either a single resistant pathogen strain or multiple strains. Strains of Staph. aureus and E. coli other than Newbould 305 and P4:O32, respectively, have been applied in the mouse mastitis model (reviewed by Brouillette and Malouin, 2005; and Notebaert and Meyer, 2006), highlighting the diversity of its possible applications. In contrast to labor-intensive and costly experimental mastitis studies in cows, an intra-experimental comparison of a panel of selected clinically relevant bovine pathogen isolates is easily achievable in mice and therefore of major added value.

The analysis in this in vivo mouse mastitis study showed the adequate antimicrobial efficacy of the novel biphenomycin compound AIC102827 against a reference strain of the 3 major bovine mastitis pathogens Staph. aureus, Strep. uberis, and E. coli. The field efficacy assessment of this promising compound in an appropriate formulation in dairy cattle is now required to validate these innovative intermediate data in the target species.

\section{ACKNOWLEDGMENTS}

The authors gratefully acknowledge the technical assistance of K. Demeyere (Laboratory of Biochemistry, Faculty of Veterinary Medicine, Ghent University, Merelbeke, Belgium). The authors declare no conflict of interest.

\section{REFERENCES}

Agirrezabala, X., and J. Frank. 2009. Elongation in translation as a dynamic interaction among the ribosome, tRNA, and elongation factors EF-G and EF-Tu. Q. Rev. Biophys. 42:159-200.

Apparao, M. D., P. L. Ruegg, A. Lago, S. Godden, R. Bey, and K. Leslie. 2009. Relationship between in vitro susceptibility test results and treatment outcomes for gram-positive mastitis pathogens following treatment with cephapirin sodium. J. Dairy Sci. 92:2589-2597.

Bradley, A. 2002. Bovine mastitis: An evolving disease. Vet. J. 164:116-128.

Bramley, A. J. 1976. Variations in the susceptibility of lactating and non-lactating bovine udders to infection when infused with Escherichia coli. J. Dairy Res. 43:205-211.

Brouillette, E., G. Grondin, C. Lefebvre, B. G. Talbot, and F. Ma louin. 2004. Mouse mastitis model of infection for antimicrobial compound efficacy studies against intracellular and extracellular forms of Staphylococcus aureus. Vet. Microbiol. 101:253-262.

Brouillette, E., and F. Malouin. 2005. The pathogenesis and control of Staphylococcus aureus-induced mastitis: Study models in the mouse. Microbes Inf. 7:560-568.

CLSI. 2008, Performance standards for antimicrobial disk and dilution susceptibility tests for bacteria isolated from animals. 3rd ed. Clinical and Laboratory Standards Institute (CLSI), Wayne, PA.

Demon, D., C. Ludwig, K. Breyne, D. Guede, J. C. Dorner, R. Froyman, and E. Meyer. 2012. The intramammary efficacy of firstgeneration cephalosporins against Staphylococcus aureus mastitis in mice. Vet. Microbiol. 160:141-150.

Ezaki, M., M. Iwami, M. Yamashita, S. Hashimoto, T. Komori, K. Umehara, Y. Mine, M. Kohsaka, H. Aoki, and H. Imanaka. 1985 Biphenomycins A and B, novel peptide antibiotics. I. Taxonomy, fermentation, isolation and characterization. J. Antibiot. (Tokyo) 38:1453-1461.

Gehring, R., and G. W. Smith. 2006. An overview of factors affecting the disposition of intramammary preparations used to treat bovine mastitis. J. Vet. Pharmacol. Ther. 29:237-241.

Hogeveen, H., C. Kamphuis, W. Steeneveld, and H. Mollenhorst. 2010. Sensors and clinical mastitis - The quest for the perfect alert. Sensors (Basel) 10:7991-8009.

McDonald, T. J., and J. S. McDonald. 1976. Streptococci isolated from bovine intramammary infections. Am. J. Vet. Res. 37:377-381.

NMC (National Mastitis Council). 2006. Recommended mastitis control program; National Mastitis Council Inc., Madison, WI. Accessed May 1, 2013. http://www.nmconline.org/docs/NMC checklistInt.pdf.

Notebaert, S., D. Demon, T. Vanden Berghe, P. Vandenabeele, and E. Meyer. 2008. Inflammatory mediators in Escherichia coli-induced mastitis in mice. Comp. Immunol. Microbiol. Infect. Dis. 31:551-565.

Notebaert, S., and E. Meyer. 2006. Mouse models to study the pathogenesis and control of bovine mastitis. A review. Vet. Q. 28:2-13.

Piepers, S., L. De Meulemeester, A. de Kruif, G. Opsomer, H. W. Barkema, and S. De Vliegher. 2007. Prevalence and distribution of mastitis pathogens in subclinically infected dairy cows in Flanders, Belgium. J. Dairy Res. 74:478-483. 
Pinzón-Sánchez, C., V. E. Cabrera, and P. L. Ruegg. 2011. Decision tree analysis of treatment strategies for mild and moderate cases of clinical mastitis occurring in early lactation. J. Dairy Sci. 94:1873-1892.

Prasad, L. B., and F. H. Newbould. 1968. Inoculation of the bovine teat duct with Staph. aureus: The relationship of teat duct length, milk yield and milking rate to development of intramammary infection. Can. Vet. J. 9:107-115.

Pyörälä, S. 2009. Treatment of mastitis during lactation. Ir. Vet. J. 62(Suppl. 4):S40-S44.

Saini, V., J. T. McClure, D. Leger, G. P. Keefe, D. T. Scholl, D. W. Morck, and H. W. Barkema. 2012. Antimicrobial resistance profiles of common mastitis pathogens on Canadian dairy farms. J. Dairy Sci. 95:4319-4332.
Van Bambeke, F., M. Barcia-Macay, S. Lemaire, and P. M. Tulkens. 2006. Cellular pharmacodynamics and pharmacokinetics of antibiotics: Current views and perspectives. Curr. Opin. Drug Discov. Devel. 9:218-230.

Zadoks, R. 2007. Sources and epidemiology of Streptococcus uberis, with special emphasis on mastitis in dairy cattle. CAB Reviews: Perspectives in Agriculture, Veterinary Science, Nutrition and Natural Resources. Vol. 2. CAB International, Wallingford, UK.

Zadoks, R. N., J. R. Middleton, S. McDougall, J. Katholm, and Y. H. Schukken. 2011. Molecular epidemiology of mastitis pathogens of dairy cattle and comparative relevance to humans. J. Mammary Gland Biol. Neoplasia 16:357-372. 